\title{
Environmental factors associated with the distribution of Loa loa vectors Chrysops spp. in Central and West Africa: seeing the forest for the trees
}

Xavier Badia-Rius, Hannah Betts, David H. Molyneux and Louise A. Kelly-Hope* (D)

\begin{abstract}
Background: Loiasis is caused by the filarial parasite Loa loa, which is widespread through Central and West Africa and largely confined the tropical equatorial rainforests. The tabanid flies Chrysops silacea and Chrysops dimidiata are the main vectors driving transmission. This study aimed to better define the spatial distribution and ecological niche of the two vectors to help define spatial-temporal risk and target appropriate, timely intervention strategies for filariasis control and elimination programmes.
\end{abstract}

Methods: Chrysops spp. distributions were determined by collating information from the published literature into a database, detailing the year, country, locality, latitude/longitude and species collected. Environmental factors including climate, elevation and tree canopy characteristics were summarised for each vector from data obtained from satellite modelled data or imagery, which were also used to identify areas with overt landcover changes. The presence of each Chrysops vector was predicted using a maximum entropy species distribution modelling (MaxEnt) method.

Results: A total of 313 location-specific data points from 59 published articles were identified across seven loiasis endemic countries. Of these, 186 sites were included in the climate and elevation analysis, and due to overt landcover changes, 83 sites included in tree canopy analysis and MaxEnt model. Overall, C. silacea and C. dimidiata were found to have similar ranges; annual mean temperature $\left(24.6{ }^{\circ} \mathrm{C}\right.$ and $24.1{ }^{\circ} \mathrm{C}$, respectively), annual precipitation (1848.6 $\mathrm{mm}$ and $1868.8 \mathrm{~mm}$ ), elevation (368.8 $\mathrm{m}$ and $400.6 \mathrm{~m}$ ), tree canopy cover (61.4\% and 66.9\%) and tree canopy height (22.4 m and $25.1 \mathrm{~m}$ ). MaxEnt models found tree canopy coverage was a significant environmental variable for both vectors.

Conclusions: The Chrysops spp. database and large-scale environmental analysis provides insights into the spatial and ecological parameters of the L. loa vectors driving transmission. These may be used to further delineate loiasis risk, which will be important for implementing filariasis control and elimination programmes in the equatorial rainforest region of Central and West Africa.

Keywords: Chrysops silacea, Chrysops dimidiata, Loa loa, Loiasis, Africa, Ecology, Climate, Environment, Rainforest, MaxEnt

\footnotetext{
* Correspondence: Louise.Kelly-Hope@lstmed.ac.uk

Department of Tropical Disease Biology, Liverpool School of Tropical

Medicine, Liverpool, UK
}

(c) The Author(s). 2019 Open Access This article is distributed under the terms of the Creative Commons Attribution 4.0 International License (http://creativecommons.org/licenses/by/4.0/), which permits unrestricted use, distribution, and reproduction in any medium, provided you give appropriate credit to the original author(s) and the source, provide a link to the Creative Commons license, and indicate if changes were made. The Creative Commons Public Domain Dedication waiver (http://creativecommons.org/publicdomain/zero/1.0/) applies to the data made available in this article, unless otherwise stated. 


\section{Background}

Loa loa (Cobbold, 1864) is a filarial nematode that causes infection and disease commonly known as loiasis, or African eye worm $[1,2]$. Loa loa is mainly transmitted by two tabanid flies of the genus Chrysops (Order Diptera: Family Tabanidae): Chrysops silacea (Austen) and C. dimidiata (Wulp), both rainforest canopy dwellers in Central and West Africa [3, 4]. Loiasis distribution has recently been mapped through large-scale community surveys based on the presence of eye worm, and is endemic in 11 countries [2]. The current distribution overlaps with historical maps, vector distributions [5-7] and the tropical dense and mosaic savanna forest region of Africa [8].

Loiasis is a major impediment for onchocerciasis and lymphatic filariasis (LF) elimination programmes implementing mass drug administration (MDA) with ivermectin, due to the risk of severe adverse events (SAEs) in individuals with high $L$. loa microfilariae (mf) levels [1, 9-12]. Loiasis is not officially classified as a neglected tropical disease (NTD), but there is increasing evidence that it is of public health importance [13]. There is a need to understand the factors driving high $L$. loa transmission as they may help to define spatial-temporal risk and target appropriate, timely intervention strategies. Environmental drivers may be particularly important given that vector-borne disease transmission is influenced by a range of climatic and landscape factors $[14,15]$.

Loiasis prevalence distributions have been associated with forest cover, landcover, vegetation, rainfall, temperature, elevation, humidity and soil types at different spatial scales using different methods, including multi-country maps and modelling [8, 16-18], comparisons between bio-ecological zones [19], and micro-scale analysis within high-risk area [20]. There is a paucity of information for Chrysops vectors; however, a recent review of historical studies highlighted that temperature, rainfall, ground water, tree height, forest coverage and/or intensity of light were identified as important factors driving vector biting and infections rates [3].

Given that $C$. silacea and $C$. dimidiata are the dominant L. loa vectors in Central and West Africa, this study aimed to better define the spatial distribution and ecological niche of the two vectors. The recent compilation of Chrysops information [3], provided the opportunity to retrospectively collate and geo-reference data, create maps, examine environmental factors and develop models associated with the presence of each vector, using advanced satellite remote sensing data, GIS technologies and the species distribution modelling tools.

\section{Methods}

Vector data and distribution map

To develop a geo-referenced database of the main $L$. loa vectors, all literature on $C$. silacea and C. dimidiata available in Kelly-Hope et al. [3] was reviewed to identify studies with location-specific data. For each study identified, the locations of all villages and/or entomological collection sites were geo-referenced using latitude and longitude coordinates obtained from the article directly and cross-checked with Google Earth Pro (https:// www.google.com/earth/). Geo-localisation of the sites without coordinates was carried out with data from Google Maps (https://www.google.com/maps), Google Earth Pro and GeoNames (http://www.geonames.org). Villages or collection sites that were not found or where the location was not precise were excluded from the database, and any repeated sites of the same species were excluded from the environmental analyses (described below). All geo-referenced Chrysops spp. were imported into the mapping software QGIS 2.14.20 [21], and a map showing the village and/or entomological collection sites of the two Chrysops spp. was created.

\section{Environmental data and analysis}

To examine environmental factors associated with the presence of $C$. silacea and $C$. dimidiata, nine climatic, topographical and forest-related variables, which are considered to affect the development and survival of vectors, were examined. First, long-term climate, and elevation data were obtained from the WorldClim 1.4 Global Climate Data (http://www.worldclim.org) at $1 \mathrm{~km}$ resolution, which used interpolations of observed data, representative of 1960-1990 [22]. The bioclimatic variables available are frequently used for species distributions and related ecological modelling. For this study, annual mean temperature (Bio1), mean temperature of the warmest quarter (Bio10), mean temperature of the coldest quarter (Bio11), annual precipitation (Bio12), precipitation of the wettest quarter (Bio16), precipitation of the driest quarter (Bio17) and elevation data were examined. The temperature measures were measured in degree Celsius $\left({ }^{\circ} \mathrm{C}\right)$, precipitation in millimetres $(\mathrm{mm})$ and elevation in metres $(\mathrm{m})$.

Secondly, as both Chrysops spp. are forest canopy dwellers, data on tree canopy height and tree canopy coverage were examined. The tree canopy coverage data, defined as canopy closure for all vegetation taller than 5 metres $(\mathrm{m})$ in height at a $30 \mathrm{~m}$ resolution and encoded as percentage (\%), were generated for the year 2000, and obtained from the Global Forest Change 2000-2016, version 1.4 (https://earthenginepartners.appspot.com/ science-2013-global-forest/download_v1.4.html) [23]. The tree canopy height $(\mathrm{m})$ data were obtained from the Global $1 \mathrm{~km}$ Forest Canopy Height modelled data generated in 2005 available from ORNL DAAC 2017 [24].

To account for the historical nature of the Chrysops spp. data and identify potential anthropogenic changes to vector habitats such as deforestation and/or urbanization, the 
levels of tree canopy coverage over time were examined. Satellite images available in Google Earth taken since the 1980s were visually compared at three-time points: 1984 , the first image available; 2000, year of the tree canopy cover variable; 2018, current. Villages and/or entomological collection sites that had overt visual changes in forest coverage were excluded from canopy height and canopy coverage analyses.

All geo-referenced Chrysops spp. and environmental data were imported into QGIS 2.14.20 [21]. First, at each village and/or entomological site a $3 \mathrm{~km}$ buffer using geoprocessing spatial tool was created. Secondly, environmental data within the buffers were extracted, and exported for descriptive and statistical analyses using IBM SPSS Statistics 24. Data were summarised, and comparisons between $C$. silacea and $C$. dimidiata conducted using the Mann-Whitney non-parametric test, with a significance level of $P \leq 0.05$.

\section{MaxEnt model and probability maps}

To predict the presence of $C$. silacea and $C$. dimidiata using environmental data, a maximum entropy species distribution modelling (MaxEnt) method was used [25]. The MaxEnt software (version 3.4.1), is a general-purpose learning method, which uses presence-only (i.e. occurrence) data and environmental variables to help define the distribution of the maximum entropy (i.e. closest to uniform) [25-27].

Data points where tree cover had changed over time, i.e. between 1984-2018, were excluded from the analysis. Environmental data included one main temperature and precipitation variable to account for collinearity between the related sub-variables. Elevation was excluded as it was used as a covariate in the WorldClim data production. To account for the different spatial resolutions between WorldClim $(1 \mathrm{~km})$, tree canopy coverage $(30 \mathrm{~m})$ data and tree canopy height $(1 \mathrm{~km})$, re-sampling of the tree cover variable to $1 \times 1 \mathrm{~km}$ using a bilinear interpolation was conducted in QGIS 2.14.20 [28, 29]. All layers were converted to ASCII (American Standard Code for Information Interchange) format for MaxEnt model use [26].

Thirty replicates of each model for each Chrysops spp. were generated by bootstrapping $[29,30]$. To evaluate model performance, the data was randomly split in two parts: $75 \%$ of the occurrence data was selected as training data to fit the model and $25 \%$ as validation data to evaluate model prediction. The maximum number of background points was set to 10,000 and continuous maps of Chrysops spp. suitability were obtained by logistic output, which illustrates an estimated probability of presence in terms of probability values ranging from 0 (unsuitable) to 1 (highest suitability) [30].

Threshold independent area under the curve (AUC) was used to interpret the performance of the model.
AUC values range from 0 to 1 where 0.5 represents random prediction. For instance, a value of 0.8 indicates that there is a 0.8 probability that a random selected occurrence point has greater predicted suitability value than a random background point [30]. Jackknife test and variable contribution table assessed the importance of each environmental variable in isolation as well as when it was omitted. Finally, the response curves of how the probability of presence changed along different values of each variable was examined [26].

A spatial distribution map was produced representing the probability of occurrence in form of percentages for both vectors $C$. silacea and $C$. dimidiata. The data were obtained from MaxEnt model results and the maps were created using QGIS 2.14.20 [21].

\section{Results}

\section{Chrysops spp. points distribution}

In total, 59 articles published between 1912 and 2013 with 313 location-specific data points across Central and West Africa were identified (Fig. 1). Of these, 28 data points were excluded due to lack of a precise location, and 99 data points excluded as they were repeats, i.e. vector collections conducted in the same place at different times. The remaining 186 data points were in Cameroon $(n=65)$, Nigeria $(n=48)$, Equatorial Guinea

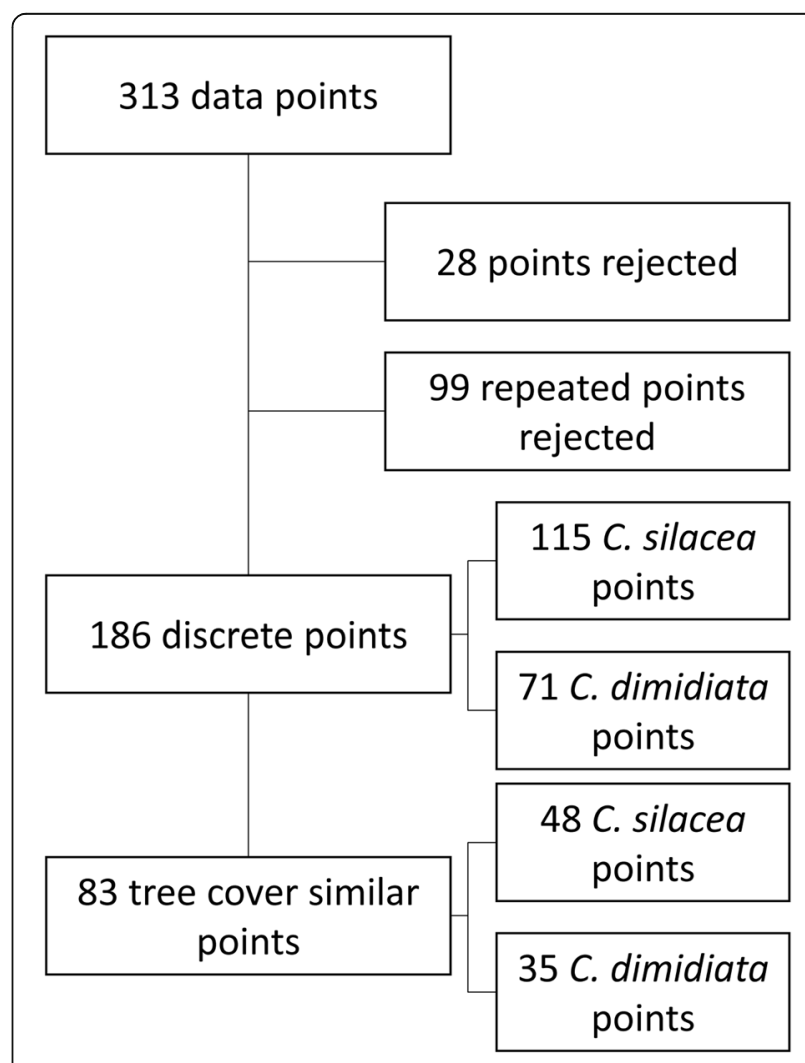

Fig. 1 Diagram of methodology used in Chrysops data points 
$(n=10)$, South Sudan $(n=2)$, Democratic Republic of Congo (DRC; $n=43$ ), Republic of Congo (Congo; $n=$ $16)$ and Gabon $(n=2)$ (Additional file 1: Table S1). The vector $C$. silacea was recorded in 115 sites and $C$. dimidiata in 71 sites. The distribution of both vectors was similar, and they overlapped in many regions, particularly in Cameroon as shown in Fig. 2.

\section{Climatic and topographical associations}

The summary of the different long-term climate and elevation variables for each species in each country are shown in Table 1. Overall, the environmental parameters for $C$. silacea and $C$. dimidiata were similar and within defined ranges; annual mean temperature $\left(24.6{ }^{\circ} \mathrm{C}\right.$ and $24.1{ }^{\circ} \mathrm{C}$, respectively), mean temperature of the warmest quarter $\left(25.7^{\circ} \mathrm{C}\right.$ and $\left.25.1{ }^{\circ} \mathrm{C}\right)$, mean temperature of the coldest quarter $\left(23.3{ }^{\circ} \mathrm{C}\right.$ and $\left.22.8^{\circ} \mathrm{C}\right)$, annual precipitation (1848.6 $\mathrm{mm}$ and $1868.8 \mathrm{~mm}$ ), precipitation in the wettest quarter $(778.3 \mathrm{~mm}$ and $789.9 \mathrm{~mm})$, precipitation in the driest quarter $(94.5 \mathrm{~mm}$ and $100.5 \mathrm{~mm})$ and elevation (368.8 $\mathrm{m}$ and $400.6 \mathrm{~m}$ ). However, C. silacea was found to have a significantly higher annual mean temperature, mean temperature of the warmest quarter, mean temperature of the coldest quarter than $C$. dimidiata $(U=$ -2.460; $P=0.014 ; U=-2.694 ; P=0.007$; and $U=-1.999 ; P$ $=0.046$, respectively). Overall, there were no significant differences between the vectors for the precipitation and elevation parameters. Interestingly, the country means range for the variables mean temperature of the warmest quarter and coldest quarter was $28{ }^{\circ} \mathrm{C}$ and $17{ }^{\circ} \mathrm{C}$, respectively.

Comparisons between countries found that the C. silacea and $C$. dimidiata sites in Nigeria had a higher mean annual temperature $\left(26.4{ }^{\circ} \mathrm{C}\right.$ and $26.5{ }^{\circ} \mathrm{C}$, respectively), higher annual precipitation (2063.5 $\mathrm{mm}$ and $2448.4 \mathrm{~mm}$ ) and lower elevation $(127.0 \mathrm{~m}$ and $39.4 \mathrm{~m})$ than all other countries; however, only a few data points were available for Equatorial Guinea, Gabon and South Sudan (Table 1).

\section{Tree canopy associations}

Examination of satellite images available in Google Earth found that 103 of the 186 sites $(55.4 \%)$ had overt landcover changes and were excluded from tree canopy analysis. Two examples of sites with minimal landcover changes and two with overt landcover changes are presented in Additional file 2: Figure S1. The exclusion of the sites with overt changes resulted in 48 sites for $C$. silacea and 35 sites for $C$. dimidiata available for analyses and their distribution is shown in Fig. 1.

Overall the mean tree canopy height and canopy coverage for $C$. silacea sites were lower $(22.4 \mathrm{~m}$ and $61.4 \%$, respectively) than those for $C$. dimidiata sites (25.1 $\mathrm{m}$ and $66.9 \%$ ) (Table 2); however, the differences were not statistically significant.

Comparisons between countries found that C. silacea highest mean canopy height was in Cameroon $(29.0 \mathrm{~m})$ and Equatorial Guinea $(26.0 \mathrm{~m})$, and the highest canopy coverage was in DRC (72.3\%) and Congo (74.3\%); however, only a few data points were available for Equatorial

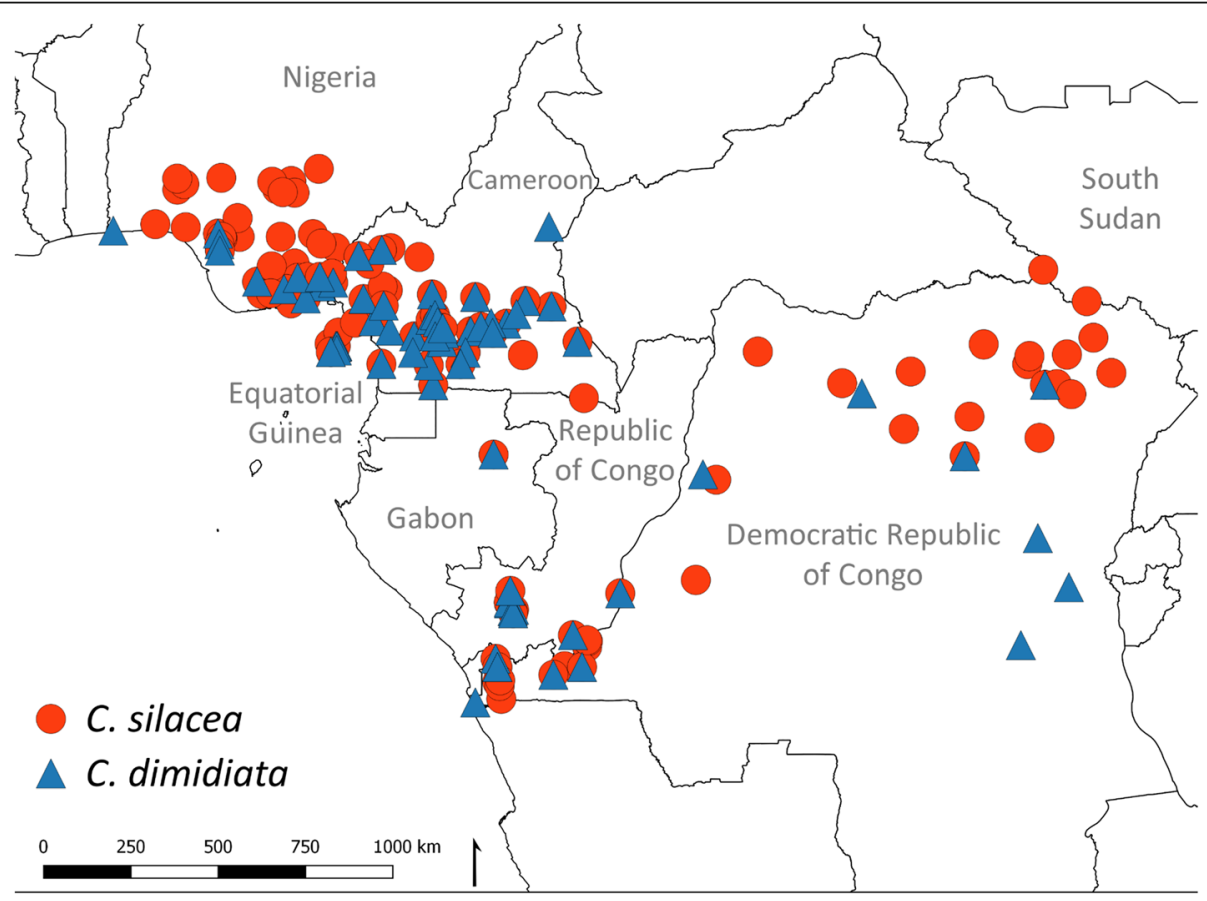

Fig. 2 Map of Chrysops locations in the Central African countries 
Table 1 Descriptive statistics of the different environmental variables by vector species and country

\begin{tabular}{|c|c|c|c|c|c|c|c|c|c|c|}
\hline Species & Country & $n$ & Statistic & $\begin{array}{l}\text { Annual mean } \\
\text { temperature } \\
\left({ }^{\circ} \mathrm{C}\right)\end{array}$ & $\begin{array}{l}\text { Mean } \\
\text { temperature } \\
\text { warmest quarter } \\
\left({ }^{\circ} \mathrm{C}\right)\end{array}$ & $\begin{array}{l}\text { Mean } \\
\text { temperature } \\
\text { coldest quarter } \\
\left({ }^{\circ} \mathrm{C}\right)\end{array}$ & $\begin{array}{l}\text { Annual } \\
\text { precipitation } \\
(\mathrm{mm})\end{array}$ & $\begin{array}{l}\text { Precipitation } \\
\text { wettest } \\
\text { quarter (mm) }\end{array}$ & $\begin{array}{l}\text { Precipitation } \\
\text { driest quarter } \\
(\mathrm{mm})\end{array}$ & $\begin{array}{l}\text { Elevation } \\
\text { (m) }\end{array}$ \\
\hline \multirow[t]{16}{*}{ C. silacea } & \multirow[t]{2}{*}{ Cameroon } & \multirow[t]{2}{*}{33} & Mean & 23.4 & 24.3 & 22.4 & 1939.0 & 854.8 & 103.0 & 550.1 \\
\hline & & & SD & 2.7 & 2.8 & 2.7 & 474.3 & 269.8 & 38.0 & 313.7 \\
\hline & \multirow[t]{2}{*}{ DRC } & \multirow[t]{2}{*}{30} & Mean & 24.9 & 25.9 & 23.4 & 1596.4 & 591.4 & 123.2 & 448.3 \\
\hline & & & SD & 0.8 & 1.0 & 1.1 & 324.3 & 57.7 & 108.6 & 216.6 \\
\hline & \multirow{2}{*}{$\begin{array}{l}\text { Equatorial } \\
\text { Guinea }\end{array}$} & \multirow[t]{2}{*}{4} & Mean & 18.0 & 18.6 & 17.3 & 1832.2 & 772.8 & 114.0 & 201.4 \\
\hline & & & SD & 2.7 & 2.8 & 2.6 & 431.4 & 190.2 & 25.3 & 206.5 \\
\hline & \multirow[t]{2}{*}{ Gabon } & \multirow[t]{2}{*}{1} & Mean & 24.0 & 24.9 & 22.4 & 1646.1 & 668.6 & 93.1 & 493.6 \\
\hline & & & SD & - & - & - & - & - & - & - \\
\hline & \multirow[t]{2}{*}{ Nigeria } & \multirow[t]{2}{*}{37} & Mean & 26.4 & 27.8 & 25.0 & 2063.5 & 901.0 & 81.7 & 127.0 \\
\hline & & & SD & 0.7 & 0.7 & 0.8 & 597.5 & 253.4 & 44.5 & 137.0 \\
\hline & \multirow[t]{2}{*}{ Congo } & \multirow[t]{2}{*}{8} & Mean & 23.9 & 25.1 & 21.8 & 1559.8 & 657.2 & 13.0 & 428.6 \\
\hline & & & SD & 0.9 & 0.7 & 1.3 & 85.7 & 53.5 & 13.5 & 55.1 \\
\hline & \multirow{2}{*}{$\begin{array}{l}\text { South } \\
\text { Sudan }\end{array}$} & \multirow[t]{2}{*}{2} & Mean & 24.7 & 26.0 & 23.5 & 1454.3 & 597.8 & 46.1 & 687.7 \\
\hline & & & SD & 0.3 & 0.6 & 0.0 & 3.4 & 19.4 & 2.5 & 49.8 \\
\hline & \multirow[t]{2}{*}{ Overall } & \multirow[t]{2}{*}{115} & Mean & 24.6 & 25.7 & 23.3 & 1848.6 & 778.3 & 94.5 & 368.8 \\
\hline & & & SD & 2.4 & 2.6 & 2.3 & 501.0 & 245.3 & 69.8 & 283.1 \\
\hline \multirow{14}{*}{$\begin{array}{l}\text { C. } \\
\text { dimidiata }\end{array}$} & \multirow[t]{2}{*}{ Cameroon } & \multirow[t]{2}{*}{32} & Mean & 23.7 & 24.6 & 22.7 & 1849.5 & 794.9 & 103.8 & 540.1 \\
\hline & & & SD & 2.5 & 2.6 & 2.4 & 435.4 & 229.1 & 35.6 & 275.6 \\
\hline & \multirow[t]{2}{*}{ DRC } & \multirow[t]{2}{*}{13} & Mean & 24.6 & 25.6 & 23.0 & 1505.2 & 572.2 & 123.8 & 415.0 \\
\hline & & & $\mathrm{SD}$ & 0.7 & 0.9 & 1.3 & 359.2 & 64.8 & 128.8 & 230.2 \\
\hline & \multirow{2}{*}{$\begin{array}{l}\text { Equatorial } \\
\text { Guinea }\end{array}$} & \multirow[t]{2}{*}{6} & Mean & 21.0 & 21.6 & 20.1 & 2145.8 & 906.6 & 127.2 & 235.1 \\
\hline & & & SD & 3.4 & 3.5 & 3.3 & 385.5 & 159.5 & 23.3 & 150.9 \\
\hline & \multirow[t]{2}{*}{ Gabon } & \multirow[t]{2}{*}{1} & Mean & 24.0 & 24.9 & 22.4 & 1646.1 & 668.6 & 93.1 & 493.6 \\
\hline & & & SD & - & - & - & - & - & - & - \\
\hline & \multirow[t]{2}{*}{ Nigeria } & \multirow[t]{2}{*}{11} & Mean & 26.5 & 27.6 & 25.3 & 2448.4 & 1076.2 & 113.2 & 39.4 \\
\hline & & & SD & 0.4 & 0.5 & 0.3 & 447.5 & 165.1 & 27.4 & 35.9 \\
\hline & Congo & 8 & Mean & 23.9 & 25.1 & 21.8 & 1559.8 & 657.2 & 13.0 & 428.6 \\
\hline & & & SD & 0.9 & 0.7 & 1.3 & 85.7 & 53.5 & 13.5 & 55.1 \\
\hline & Overall & 71 & Mean & 24.1 & 25.1 & 22.8 & 1868.8 & 789.9 & 100.5 & 400.6 \\
\hline & & & SD & 2.4 & 2.5 & 2.3 & 491.7 & 234.6 & 68.1 & 277.2 \\
\hline
\end{tabular}

Abbreviation: DRC Democratic Republic of the Congo, SD standard deviation

Guinea and South Sudan. For the C. dimidiata sites, the highest canopy height was found in DRC $(28.0 \mathrm{~m})$ and Equatorial Guinea $(29.4 \mathrm{~m})$, and the highest canopy coverage in DRC (73.2\%) and Congo (74.3\%); however, only a few data points were available for Nigeria (Table 2).

\section{MaxEnt model and probability maps}

The MaxEnt model included 83 sites (48 for C. silacea and 35 for $C$. dimidiata) and the mean annual temperature, annual precipitation, tree canopy height and tree canopy coverage variables. For $C$. silacea, the model had a mean training AUC of $0.911 \pm 0.015$ of 30 bootstrapping replications, and for $C$. dimidiata, the model had a mean training AUC of $0.941 \pm 0.014$, which demonstrated that both models had a robust prediction of the distribution of Chrysops vectors. The AUC plot for $C$. silacea and C. dimidiata are shown in Fig. $3 \mathrm{a}$ and b, respectively. The jackknife test for both species had similar variable contributions. For C. silacea, the annual precipitation was the most important variable if considered in isolation. However, if a multivariate model was considered, tree canopy coverage was the variable which when omitted reduced the fit of the model the most (Fig. 3c). For $C$. dimidiata, tree canopy coverage was the most important variable if considered in isolation. Furthermore, it was also the variable which reduced the fit of 
Table 2 Descriptive statistics of canopy height and tree canopy cover variables by species and country

\begin{tabular}{|c|c|c|c|c|c|}
\hline Species & Country & $n$ & Statistic & Canopy height (m) & Tree cover (\% canopy > $5 \mathrm{~m}$ ) \\
\hline \multirow[t]{14}{*}{ C. silacea } & \multirow[t]{2}{*}{ Cameroon } & \multirow[t]{2}{*}{12} & Mean & 29.0 & 65.0 \\
\hline & & & SD & 5.4 & 13.3 \\
\hline & \multirow[t]{2}{*}{ DRC } & \multirow[t]{2}{*}{14} & Mean & 20.7 & 72.3 \\
\hline & & & SD & 10.7 & 19.2 \\
\hline & \multirow[t]{2}{*}{ Equatorial Guinea } & \multirow[t]{2}{*}{3} & Mean & 26.0 & 56.2 \\
\hline & & & SD & 5.0 & 18.1 \\
\hline & \multirow[t]{2}{*}{ Nigeria } & \multirow[t]{2}{*}{10} & Mean & 17.3 & 34.0 \\
\hline & & & SD & 9.8 & 21.4 \\
\hline & \multirow[t]{2}{*}{ Congo } & \multirow[t]{2}{*}{8} & Mean & 21.1 & 74.3 \\
\hline & & & SD & 6.2 & 21.3 \\
\hline & \multirow[t]{2}{*}{ South Sudan } & \multirow[t]{2}{*}{1} & Mean & 15.7 & 51.9 \\
\hline & & & SD & - & - \\
\hline & \multirow[t]{2}{*}{ Overall } & \multirow[t]{2}{*}{48} & Mean & 22.4 & 61.4 \\
\hline & & & SD & 9.1 & 23.3 \\
\hline \multirow[t]{12}{*}{ C. dimidiata } & \multirow[t]{2}{*}{ Cameroon } & \multirow[t]{2}{*}{12} & Mean & 28.0 & 62.3 \\
\hline & & & SD & 5.9 & 12.6 \\
\hline & \multirow[t]{2}{*}{ DRC } & \multirow[t]{2}{*}{7} & Mean & 20.2 & 73.2 \\
\hline & & & SD & 12.6 & 23.1 \\
\hline & \multirow[t]{2}{*}{ Equatorial Guinea } & \multirow[t]{2}{*}{6} & Mean & 29.4 & 63.2 \\
\hline & & & SD & 5.9 & 16.8 \\
\hline & \multirow[t]{2}{*}{ Nigeria } & \multirow[t]{2}{*}{2} & Mean & 27.0 & 53.0 \\
\hline & & & SD & 8.1 & 27.1 \\
\hline & \multirow[t]{2}{*}{ Congo } & \multirow[t]{2}{*}{8} & Mean & 21.1 & 74.3 \\
\hline & & & SD & 6.2 & 21.3 \\
\hline & \multirow[t]{2}{*}{ Overall } & \multirow[t]{2}{*}{35} & Mean & 25.1 & 66.9 \\
\hline & & & SD & 8.3 & 18.5 \\
\hline
\end{tabular}

Abbreviation: DRC Democratic Republic of the Congo, SD standard deviation

the model the most when it was omitted in a multivariate model (Fig. 3d). The permutation of the environmental variables in the model indicated that annual precipitation contributed the most for both $C$. silacea and $C$. dimidiata as shown in Table 3.

The response curves highlighted how prediction is affected by each variable. Both species had similar response curve distributions as shown in Fig. 4 a-h. The mean temperature for $C$. silacea indicated a broader temperature niche (Fig. 4a) than for C. dimidiata (Fig. 4b). The annual precipitation was similar for both species at 2700 $\mathrm{mm}$; however, the likelihood of $C$. silacea presence was reduced when precipitation was higher than $2700 \mathrm{~mm}$ (Fig. 4c), but this reduction was not observed for $C$. dimidiata (Fig. 4d). For both species, tree canopy coverage higher than $80 \%$ was not suitable (Fig. 4 e, f). Canopy height response curve was found to have high variation due to its low importance in the prediction (Fig. 4g, h).

The predicted distribution of both Chrysops vectors from MaxEnt model is shown in Fig. 5a, b. Overall, the distributions were similar; however, C. silacea had higher probabilities of occurrence than $C$. dimidiata. The areas with the highest suitability were in southern Nigeria, in southern-central and western Cameroon, in Bioko Island of Equatorial Guinea, all of Gabon, in southern-central Congo, in western and north-eastern DRC, in central CAR and northern Angola.

\section{Discussion}

To our knowledge, this is the first study to collate, geolocate and analyse environmental factors related to the two main vectors responsible for $L$. loa transmission in Central and West Africa. The study highlights the need for more current data on the spatial distribution and ecology of $C$. silacea and $C$. dimidiata, which is fundamental todelineating the risk of filariasis for control and elimination programmes. While there were limitations with using historical vector data, the examination of long-term satellite-derived climate data and landcover changes helped to address these limitations. The results 
a Average sensitivity vs. 1-specificity for $C$. silacea

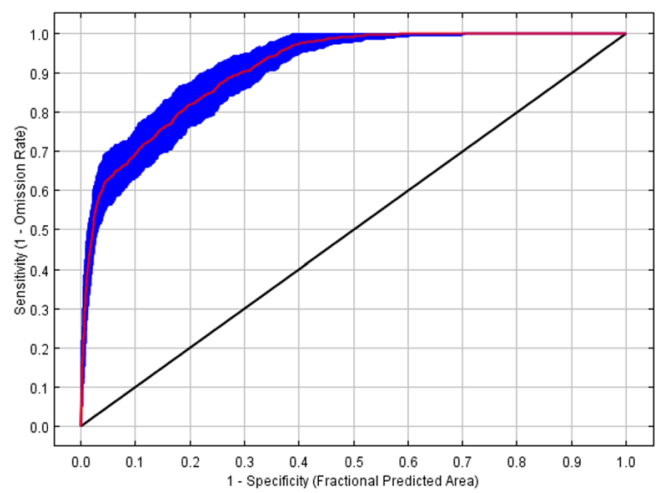

C Jacknife of regularized training gain for $C$. silacea

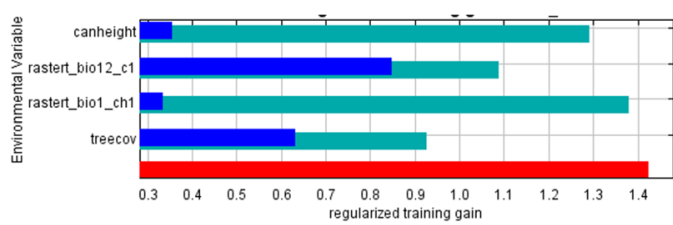

b Average sensitivity vs. 1-specificity for $C$. dimidiata

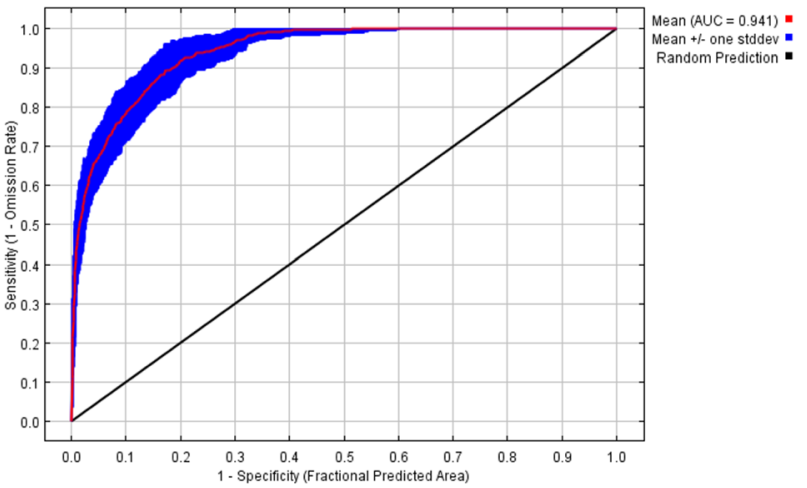

d Jacknife of regularized training gain for $C$. dimidiata

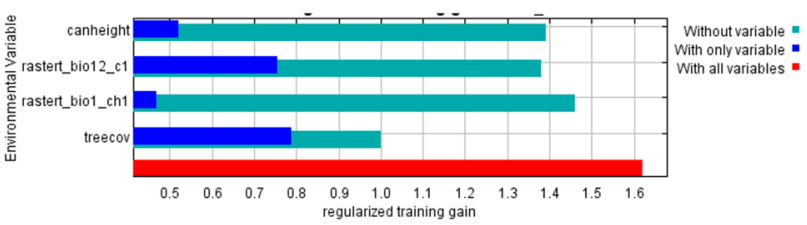

Fig. 3 MaxEnt model results plots. a, b Area under the curve (AUC) plots of both species models. Red line shows the mean of the 30 replicate MaxEnt runs and blue area the mean \pm one standard deviation. c, d Jackknife test of regularized training gain. Dark blue columns show how would be the model gain using each variable in isolation. Light blue columns show how would change the model gain if the variable was excluded. The longest dark blue column turns to be the variable to have the most useful information by itself. The shortest light blue column appears to be the variable which has the most information that is not present in other variables

provide several insights into the ecological niche or bio-climate envelope of the two Chrysops vectors, and help to define a range of key climatic, topographic and tree canopy parameters using advanced satellite remote sensing data, GIS technologies and the species distribution modelling tools.

Overall, no major differences between the two species were found, apart from temperature where $C$. silacea was found in warmer locations than $C$. dimidiata. Historical studies highlight that temperature is an important factor influencing transmission. For C. silacea, vector monthly and/or daily temperatures around $20-28{ }^{\circ} \mathrm{C}$ have been shown to be optimal for larvae development,

Table 3 Permutation importance of the environmental variables in the MaxEnt model

\begin{tabular}{lll}
\hline Variable & \multicolumn{2}{l}{ Permutation importance (\%) } \\
\cline { 2 - 3 } & C. silacea & C. dimidiata \\
\hline Annual mean temperature & 13.1 & 35 \\
Annual precipitation & 48.8 & 25.4 \\
Tree cover & 23.3 & 22.9 \\
Canopy height & 14.8 & 16.6 \\
\hline
\end{tabular}

Note. Permutation importance depends only on the final MaxEnt model. The contribution for each variable is determined by randomly permuting the values of that variable among the training points (both presence and background) and measuring the resulting decrease in training AUC. Values are normalized to give percentages adult density, biting and infection rates [31, 32]. Temperatures lower than $20{ }^{\circ} \mathrm{C}$ either in laboratory or very shaded field conditions have shown to delay larvae development in the fly. Noireau et al. [33] reported monthly temperatures, and Crewe \& O'Rourke [34] examined hourly temperature fluctuations and found the highest biting activity occurred when temperatures were around $24-27{ }^{\circ} \mathrm{C}$. Interestingly, these finer scale spatial and temporal observations correlate with our large-scale environmental analysis and models, which identify temperature in the mid-20s ${ }^{\circ} \mathrm{C}$ as an important climatic measure.

The level of precipitation in different tropical forest settings may influence the amount of nutrient rich leaves decaying in wet mud available for Chrysops larval breeding habitats [3]. Annual precipitation was found to be at least $1500 \mathrm{~mm}$ across all countries for both vectors, with the mean rainy season measures (wettest quarter) ranging between 572-1076 $\mathrm{mm}$ and mean dry season measures (driest quarter) between 13-127 mm. This study did not examine Chrysops temporal conditions; however, several studies have shown that the highest vector biting densities and/or infectivity rates occur during or after the rainy season when ground water and soil moisture may be optimal for breeding [33, 35-37]. Determining the relationship between transmission and precipitation may help to 


\section{C. silacea}

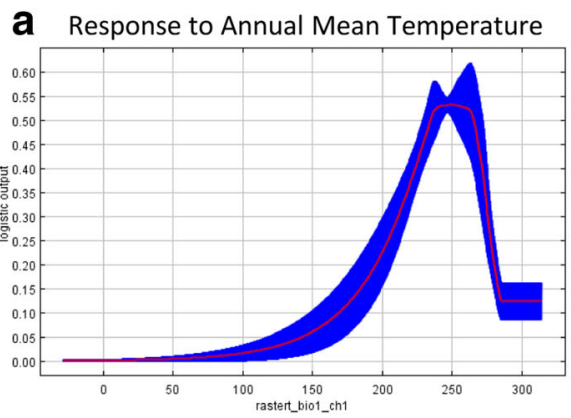

C Response to Annual Precipitation

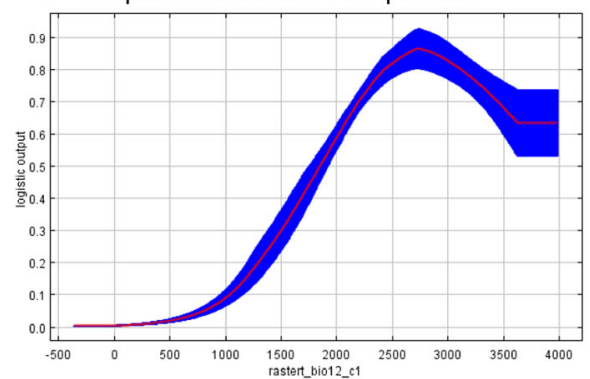

e Response to Tree Coverage

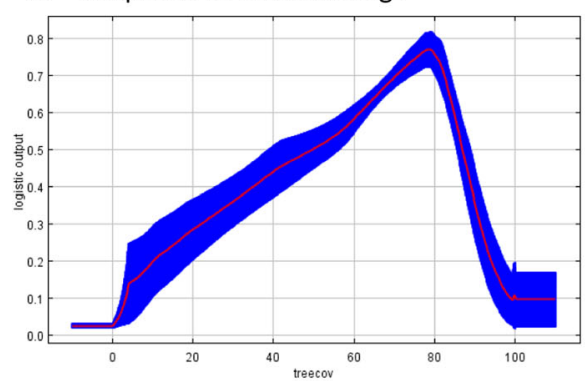

9 Response to Canopy Height

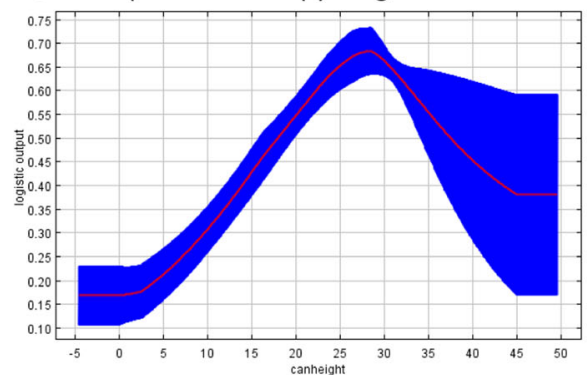

\section{C. dimidiata}

b Response to Annual Mean Temperature

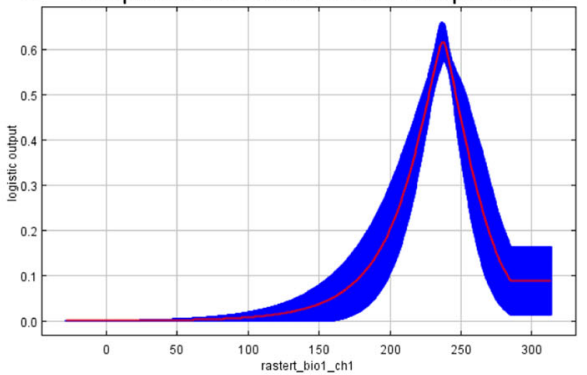

d Response to Annual Precipitation

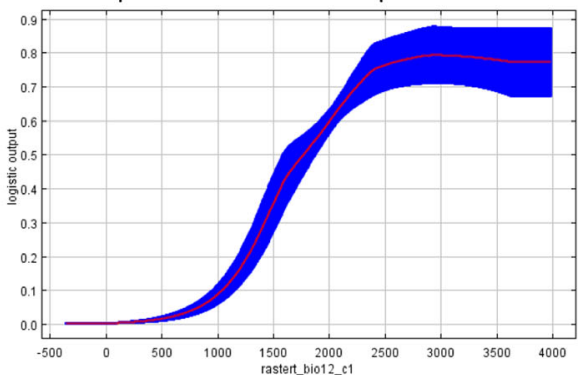

f Response to Tree Coverage

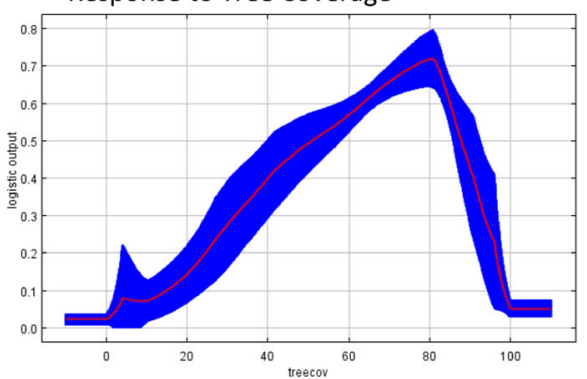

h Response to Canopy Height

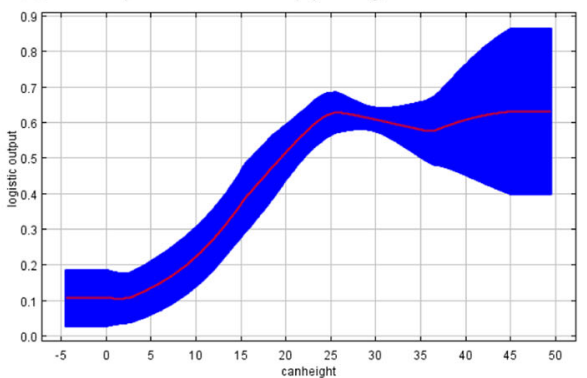

Fig. 4 Response curves of environmental variables in the two MaxEnt models for C. silacea (a, c, e, g) and C. dimidiata (b, d, f, h). The plots represent a MaxEnt model created using only the corresponding variable. The curves show the mean response of the 30 replicate MaxEnt runs (red line) and the mean \pm one standard deviation (blue area)

develop a 'L. loa transmission calendar' highlighting high-risk times [14].

Historical studies also suggest that the extent of forest cover and intensity of light influence transmission [31, 38-40]. In general, Chrysops have shown to avoid extreme conditions, including bright sunlight in cleared areas and deep shade in heavily forested areas, with only certain levels of forest and illumination associated with high biting rates. Differences between species have also been found with $C$. silacea being more dominant in cleared forested areas, particularly in villages and their immediate vicinity, and $C$. dimidiata being more closely associated with forested areas [41]. This broadly correlates with our results, which found mean tree canopy coverage was not less than $34 \%$ (i.e. cleared areas) or more than $74 \%$ (i.e. heavily forested or shaded areas), 


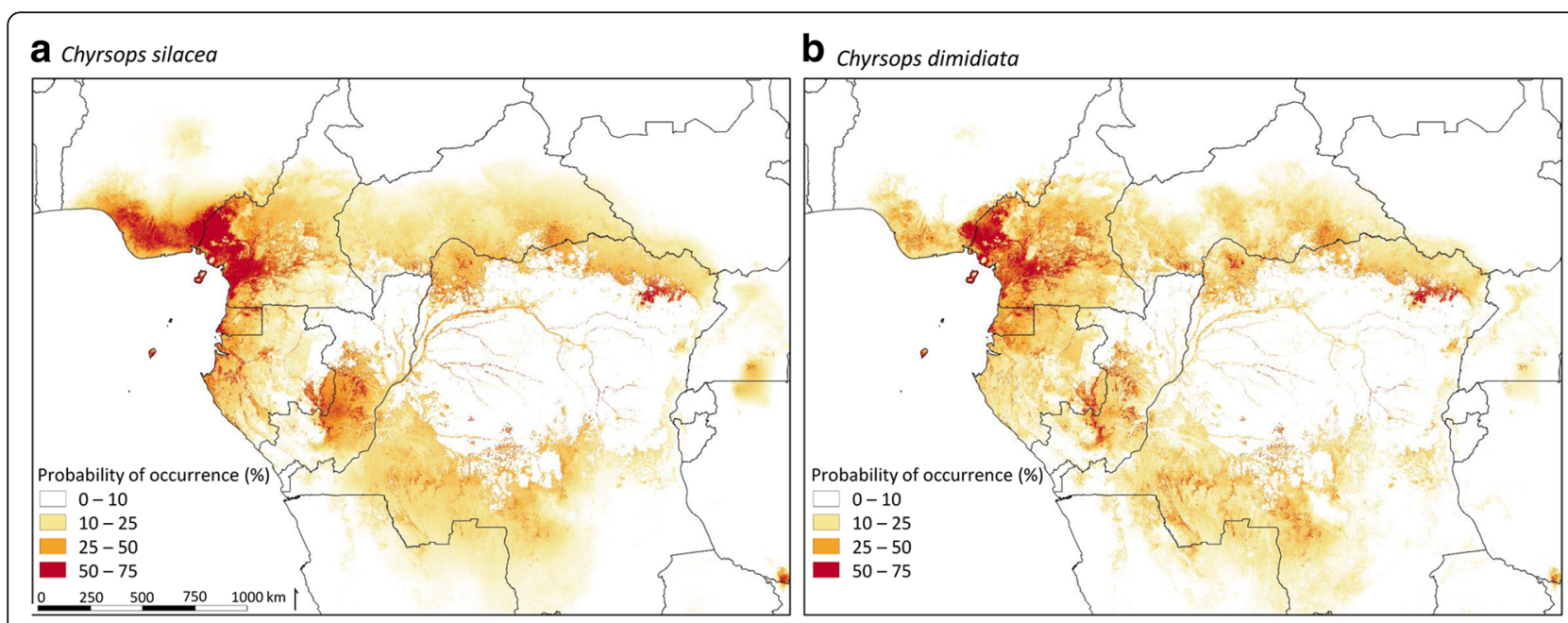

Fig. 5 Predicted distribution maps for C. silacea (a) and C. dimidiata (b) vectors obtained from MaxEnt model data. Probability of occurrence is depicted in the form of percentages

and specifically that $C$. silacea sites had lower mean proportions of canopy coverage than $C$. dimidiata.

Further, landcover changes may significantly alter transmission potential, especially deforestation as it destroys Chrysops spp. habitats. Our retrospective analysis of satellite imagery highlighted that around half of the sites had overt environmental changes over the past few decades, which appeared to be related to population growth and urbanisation. This suggests that the risk of L. loa has reduced in these areas, as commercial deforestation, forest clearings caused by population growth with resultant town development and urbanisation, have been associated with a reduction in prevalence [42]. Forest clearings have also been suggested as a potential vector control intervention in certain settings in order to distance the breeding habitats from the human population [5]. This has implications for $L$. loa endemic countries in the Congo Basin region where there is widespread evidence of deforestation and development, which may change how risk is measured and the type of interventions deployed in the future.

Defining spatial-temporal patterns of Chrysops spp. and their ecological niches within communities could help to direct interventions, which may include specific vector control measures appropriate for outdoor day-biting vectors, similar to those being developed for other vector-borne diseases [43, 44]. Historical studies highlight effective Chrysops defensive control methods such as personal insecticide repellents on the skin or impregnated on clothing to prevent vector biting $[3,5]$, which may be a practical, cost-effective and scalable intervention for ecologically defined high-risk communities. Aggressive control methods have also been suggested, and indoor residual spraying (IRS) of insecticide to houses or undergrown near breeding sites, or bespoke trapping with or without insecticide, or by using wood fire as an attractant $[37,45]$, could also be directed to ecologically defined high-risk communities to help reduce the abundance and transmission potential of $L$. loa. This will help filariasis control and elimination programmes overall by reducing the numbers of infective larvae to which humans will be exposed, with the consequence of fewer adult worms producing lower levels of microfilariae, and hence the risk of SAEs.

\section{Conclusion}

The Chrysops spp. database and large-scale environmental analysis provides insights into the spatial and ecological parameters of the $L$. loa vectors driving transmission. These may be used to further delineate loiasis risk, which will be important for implementing filariasis control and elimination programmes in the equatorial rainforest region of Central and West Africa.

\section{Additional files}

Additional file 1: Table S1. Chrysops spp. location database. (XLSX 28 kb)

Additional file 2: Figure S1. Satellite images from two sites for the years 1984, 2000 and 2018. a Two site examples with similar tree cover. b Two site examples with changed tree cover. (DOCX $4054 \mathrm{~kb}$ )

\section{Abbreviations}

ASCII: American Standard Code for Information Interchange; AUC: Area under the curve; DRC: Democratic Republic of the Congo; DEC: Diethylcarbamazine; IRS: Indoor residual spraying; LF: Lymphatic filariasis; MaxEnt: Maximum entropy species distribution modelling; mf: Microfilariae; MDA: Mass drug administration; NTD: Neglected tropical diseases; WHO: World Health Organization; RAPLOA: Rapid assessment procedure for loiasis; SAE: Severe adverse events; SDAT: Spatial data access tool

Acknowledgements

Not applicable. 


\section{Funding}

XBR was supported by an Erasmus+ Training Programme funded by the European Union. HB and LAKH were supported by the Centre for Neglected Tropical Diseases, Department of Parasitology, Liverpool School of Tropical Medicine (LSTM) through a grant from the Department for International Development (DFID), UK for the elimination of lymphatic filariasis as a public health problem

\section{Availability of data and materials}

All data supporting the conclusions of this study are within the article and additional file. The datasets used for the analysis are available from the corresponding author upon reasonable request.

\section{Authors' contributions}

LAKH and DHM conceived the idea of the study. XBR collated and georeferenced all data. XBR and $\mathrm{HB}$ analysed the data, developed the maps and models. XBR and LAKH drafted the manuscript. All authors contributed to the interpretation of the results. All authors edited, read and approved the final manuscript.

\section{Ethics approval and consent to participate}

Not applicable.

\section{Consent for publication}

Not applicable.

\section{Competing interests}

The authors declare that they have no competing interests.

\section{Publisher's Note}

Springer Nature remains neutral with regard to jurisdictional claims in published maps and institutional affiliations.

Received: 6 December 2018 Accepted: 29 January 2019 Published online: 06 February 2019

\section{References}

1. Boussinesq M. Loiasis. Ann Trop Med Parasitol. 2006;100:715-31.

2. Zouré HGM, Wanji S, Noma MM, Amazigo UV, Diggle PJ, Tekle AH, et al. The geographic distribution of Loa loa in Africa: results of large-scale implementation of the rapid assessment procedure for Loiasis (RAPLOA). PLoS Negl Trop Dis. 2011;5:e1210.

3. Kelly-Hope LA, Paulo R, Thomas B, Brito M, Unnasch TR, Molyneux D. Loa loa vectors Chrysops spp.: perspectives on research, distribution, bionomics, and implications for elimination of lymphatic filariasis and onchocerciasis. Parasit Vectors. 2017:10:172.

4. Molyneux DH, Mitre E, Bockarie MJ, Kelly-Hope LA. Filaria zoogeography in Africa: ecology, competitive exclusion, and public health relevance. Trends Parasitol. 2014;30:163-9.

5. Gordon RM, Kershaw WE, Crewe W, Oldroyd H. The problem of loiasis in West Africa with special reference to recent investigations at Kumba in the British Cameroons and at Sapele in southern Nigeria. Trans R Soc Trop Med Hyg. 1950;44:11-47.

6. Fain A. Notes on the geographical distribution of the filaria L. loa and Tabanids of the genus Chrysops in the Congo and in Rwanda. Ann Soc Belg Med Trop. 1920;1969:499-530.

7. Crewe W. The bionomics of Chrysops silacea: its life history and role in the transmission of filariasis. PhD Thesis, University of Liverpool; 1956.

8. Kelly-Hope LA, Bockarie MJ, Molyneux DH. Loa loa ecology in Central Africa: role of the Congo River system. PLoS Negl Trop Dis. 2012;6:e1605.

9. Gardon J, Gardon-Wendel N, Demanga-Ngangue KJ, Chippaux JP, Boussinesq M. Serious reactions after mass treatment of onchocerciasis with ivermectin in an area endemic for Loa loa infection. Lancet. 1997;350:18-22.

10. Kelly-Hope LA, Cano J, Stanton MC, Bockarie MJ, Molyneux DH. Innovative tools for assessing risks for severe adverse events in areas of overlapping Loa loa and other filarial distributions: the application of micro-stratification mapping. Parasit Vectors. 2014;7:307.

11. Hoerauf A, Pfarr K, Mand S, Debrah AY, Specht S. Filariasis in Africa treatment challenges and prospects. Clin Microbiol Infect. 2011;17:977-85.
12. Molyneux DH, Hopkins A, Bradley MH, Kelly-Hope LA. Multidimensional complexities of filariasis control in an era of large-scale mass drug administration programmes: a can of worms. Parasit Vectors. 2014;7:363.

13. Chesnais CB, Takougang I, Paguélé M, Pion SD, Boussinesq M. Excess mortality associated with loiasis: a retrospective population-based cohort study. Lancet Infect Dis. 2017:17:108-16.

14. Kelly-Hope L, Climate TMC. Infectious Diseases. In: Thomson MC, GarciaHerrera R, Beniston M, editors. Seasonal Forecasts, Climate Change and Human Health. Dordrecht: Springer; 2008. p. 31-70. http://citeseerx.ist.psu. edu/viewdoc/download?doi=10.1.1.424.2946\&rep=rep1\&type=pdf.

15. Thomson MC, Muñoz ÁG, Cousin R, Shumake-Guillemot J. Climate drivers of vector-borne diseases in Africa and their relevance to control programmes. Infect Dis Poverty. 2018;7:81.

16. Thomson MC, Obsomer V, Dunne M, Connor SJ, Molyneux DH. Satellite mapping of Loa loa prevalence in relation to ivermectin use in West and Central Africa. Lancet. 2000;356:1077-8.

17. Diggle PJ, Thomson MC, Christensen OF, Rowlingson B, Obsomer V, Gardon J, et al. Spatial modelling and the prediction of Loa loa risk: decision making under uncertainty. Ann Trop Med Parasitol. 2007;101:499-509.

18. Kelly-Hope LA, Unnasch TR, Stanton MC, Molyneux DH. Hypo-endemic onchocerciasis hotspots: defining areas of high risk through micro-mapping and environmental delineation. Infect Dis Poverty. 2015;4:36.

19. Wanji S, Tendongfor N, Esum M, Atanga SN, Enyong P. Heterogeneity in the prevalence and intensity of loiasis in five contrasting bioecological zones in Cameroon. Trans R Soc Trop Med Hyg. 2003;97:183-7.

20. Brant TA, Okorie PN, Ogunmola O, Ojeyode NB, Fatunade SB, Davies E, et al. Integrated risk mapping and landscape characterisation of lymphatic filariasis and loiasis in South West Nigeria. Parasite Epidemiol Control. 2018; 3:21-35.

21. Development Team QGIS. QGIS Geographic Information System. Open Source Geospatial Foundation Project; 2018. https://qgis.org.

22. Hijmans RJ, Cameron SE, Parra $J L$, Jones $P G$, Jarvis A. Very high resolution interpolated climate surfaces for global land areas. Int J Climatol. 2005;25: 1965-78.

23. Hansen MC, Potapov PV, Moore R, Hancher M, Turubanova SA, Tyukavina A, et al. High-resolution global maps of 21 st-century forest cover change. Science. 2013;342:850-3.

24. Simard M, Pinto N, Fisher JB, Baccini A. Mapping forest canopy height globally with spaceborne lidar. J Geophys Res Biogeosciences. 2011;116:1-12.

25. Phillips SJ, Anderson RP, Schapire RE. Maximum entropy modeling of species geographic distributions. Ecol Modell. 2006;190:231-59.

26. Acharya BK, Cao C, Xu M, Khanal L, Naeem S, Pandit S. Present and future of dengue fever in Nepal: mapping climatic suitability by ecological niche model. Int J Environ Res Public Health. 2018;15:187.

27. Merow C, Smith MJ, Silander JA. A practical guide to MaxEnt for modeling species' distributions: what it does, and why inputs and settings matter. Ecography. 2013:36:1058-69.

28. Hundessa S, Li S, Liu DL, Guo J, Guo Y, Zhang W, et al. Projecting environmental suitable areas for malaria transmission in China under climate change scenarios. Environ Res. 2018;162:203-10.

29. Ren Z, Wang D, Ma A, Hwang J, Bennett A, Sturrock HJW, et al. Predicting malaria vector distribution under climate change scenarios in China: challenges for malaria elimination. Sci Rep. 2016:6:20604

30. Machado-Machado Elia Axinia EAA-M-M. Empirical mapping of suitability to dengue fever in Mexico using species distribution modeling. Appl Geogr. 2012;33:82-93.

31. Connal A, Connal SLM. The Development of Loa loa (Guyot) in Chrysops silacea (Austen) and in Chrysops dimidiata (Van Der Wulp). Trans R Soc Trop Med Hyg. 1922;16:64-89.

32. Crewe W. The rate of development of larvae of Loa loa in Chrysops silacea at Kumba, and the effect of temperature upon it. Ann Trop Med Parasitol. 1961;55:211-6.

33. Noireau F, Nzoulani A, Sinda D, Caubère P. Chrysops silacea and C. dimidiata seasonality and loiasis prevalence in the Chaillu mountains, Congo. Med Vet Entomol. 1991;5:413-9.

34. Crewe W, O'Rourke FJ. The biting habits of Chrysops silacea in the forest at Kumba, British Cameroons. Ann Trop Med Parasitol. 1951;45:38-50.

35. Connal A. Observations on filaria in Chrysops from West Africa. Trans R Soc Trop Med Hyg. 1921;14:108-9.

36. Noireau F, Nzoulani A, Sinda D, Itoua A. Transmission indices of Loa loa in the Chaillu Mountains, Congo. Am J Trop Med Hyg. 1990;43:282-8. 
37. Wanji S, Tendongfor N, Esum ME, Enyong P. Chrysops silacea biting densities and transmission potential in an endemic area of human loiasis in southwest Cameroon. Trop Med Int Health. 2002;7:371-7.

38. Kettle DS. The effect of light on the biting activity of Chrysops silacea (Diptera: Tabanidae). Ann Trop Med Parasitol. 1953;47:335-9.

39. Crewe W. The effect of light on the biting activity of Chrysops silacea in the forest at Kumba, British Cameroons. Ann Trop Med Parasitol. 1953;47:340-3.

40. Duke BO. Studies on the biting habits of Chrysops. I. The biting-cycle of Chrysops silacea at various heights above the ground in the rain-forest at Kumba, British Cameroons. Ann Trop Med Parasitol. 1955;49:193-202.

41. Noireau F, Nzoulani A, Sinda D, Itoua A. Chrysops silacea and C. dimidiata: fly densities and infection rates with Loa loa in the Chaillu mountains, Congo Republic. Trans R Soc Trop Med Hyg. 1990;84:153-5.

42. Duke BO. Studies on the biting habits of Chrysops. IV. The dispersal of Chrysops silacea over cleared areas from the rain-forest at Kumba, British Cameroons. Ann Trop Med Parasitol. 1955;49:368-75.

43. Govella NJ, Ogoma SB, Paliga J, Chaki PP, Killeen G. Impregnating hessian strips with the volatile pyrethroid transfluthrin prevents outdoor exposure to vectors of malaria and lymphatic filariasis in urban Dar es Salaam, Tanzania. Parasit Vectors. 2015;8:322

44. Lehane M, Alfaroukh I, Bucheton B, Camara M, Harris A, Kaba D, et al. Tsetse control and the elimination of Gambian sleeping sickness. PLoS Negl Trop Dis. 2016;10:e0004437.

45. Duke BO. Studies on the biting habits of Chrysops. II. The effect of wood fires on the biting density of Chrysops silacea in the rain-forest at Kumba, British Cameroons. Ann Trop Med Parasitol. 1955;49:260-72.

Ready to submit your research? Choose BMC and benefit from:

- fast, convenient online submission

- thorough peer review by experienced researchers in your field

- rapid publication on acceptance

- support for research data, including large and complex data types

- gold Open Access which fosters wider collaboration and increased citations

- maximum visibility for your research: over $100 \mathrm{M}$ website views per year

At $\mathrm{BMC}$, research is always in progress.

Learn more biomedcentral.com/submissions 